\title{
A HISTÓRIA DO DESIGN DE PRODUTO NO CURSO DE DESIGN DE PRODUTO DA UFPR
}

Alberto Ireneu Puppi - alberto.puppi@ufpr.br

Universidade Federal do Paraná

A HISTÓRIA DO DESIGN DE PRODUTO é uma disciplina anual ofertada no primeiro dos quatro anos do curso.

Ela faz parte de uma sequência de outras duas disciplinas subsequentes de história na grade horária, as duas de história da arte.

Mas há outra sequência que considero de fundamental importância: HISTÓRIA DO DESIGN DE PRODUTO - SEMIÓTICA APLICADA AO DESIGN DE PRODUTO (também ministrada por mim). Importante porque a semiótica peirceana me permite lançar uma visada crítica e rearranjadora da linearidade temporal da história do design de produto.

\section{FOCO, RECORTE TEMPORAL E GEOGRÁFICO}

O foco da disciplina é centrado na história do design internacional, com eventuais abordagens da história do design brasileiro, e minha abordagem temática procura privilegiar a história dos produtos projetados pelos designers.

$\mathrm{Na}$ disciplina não trabalho numa perspectiva linear de evolução cronológica do design à moda de Nikolaus Pevsner, uma perspectiva do tipo "de William Morris a Walter Gropius" [PEVSNER, 1980]. Ao contrário, trabalho com quatro linhas evolutivas distintas que se desenrolam, cada uma delas com um passado e um presente distintos (conf. a Figura $1^{1}$ abaixo, que dá uma ideia geral de como essas quatro linhas de tempo se comportam em conjunto):

\footnotetext{
${ }^{1}$ Minha intenção na Figura 1 é mostrar apenas a visão geral do conjunto. Cada uma dessas linhas de tempo será detalhada ao longo do texto.
}

Puppi, Alberto Ireneu. "A História do Design de Produto no curso de Design de Produto da UFPR", in Anais do 1o Seminário Paulista do ensino da história do design 2014 [= Blucher Design 
1) História do Design Decorativo;

2) História do Design Funcionalista;

3) História do Styling;

4) História do Design Pós- Modernista.

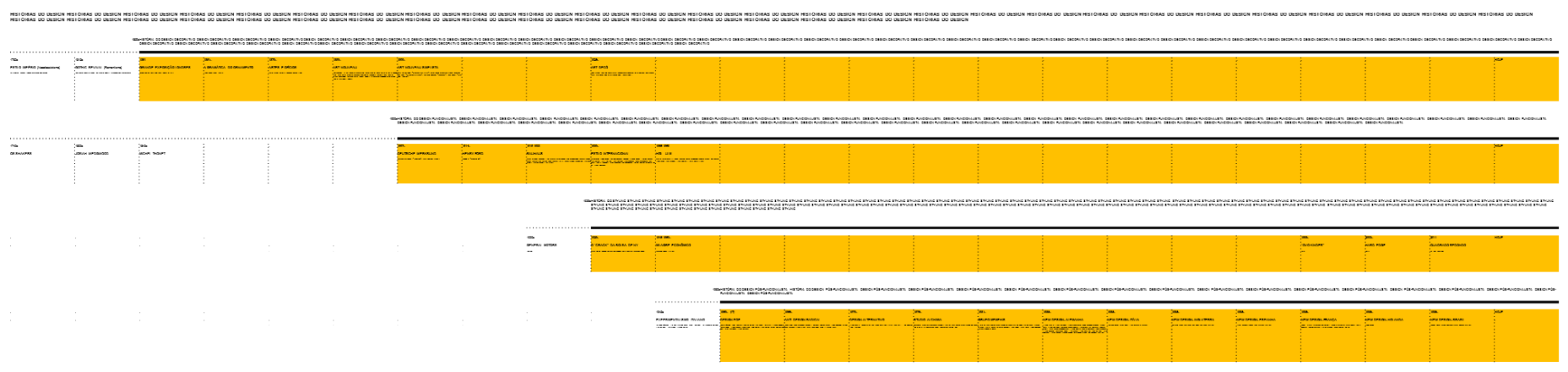

Figura 1 - As quatro linhas evolutivas da História do Design na UFPR.

Provavelmente fui movido por uma espécie de "vício do ofício" semiótico para acabar trabalhando com estas quatro linhas evolutivas distintas e independentes entre si. Mas a descoberta de que Walter Gropius não era uma espécie de sobrinho-neto de William Morris, como sugeria Pevsner [1980] e como aprendemos na escola, certamente também contribuiu para esta espécie de desconstrução da unidade histórica. 


\subsection{HISTÓRIA DO DESIGN DECORATIVO}

O recorte temporal da História do Design Decorativo começa a partir dos teóricos e designers principalmente ingleses do séc. XIX, os quais começaram a perceber a necessidade de promover uma reforma nas artes aplicadas que vinham sendo deformadas pela indústria da época [PEVSNER, 1980]. Este recorte acompanha o esforço de Owen Jones e o exemplo de William Morris, passa pela internacionalização ocidental do movimento Art Nouveau, culmina com o ArtDecó, perde força, mas não termina e persiste até hoje.

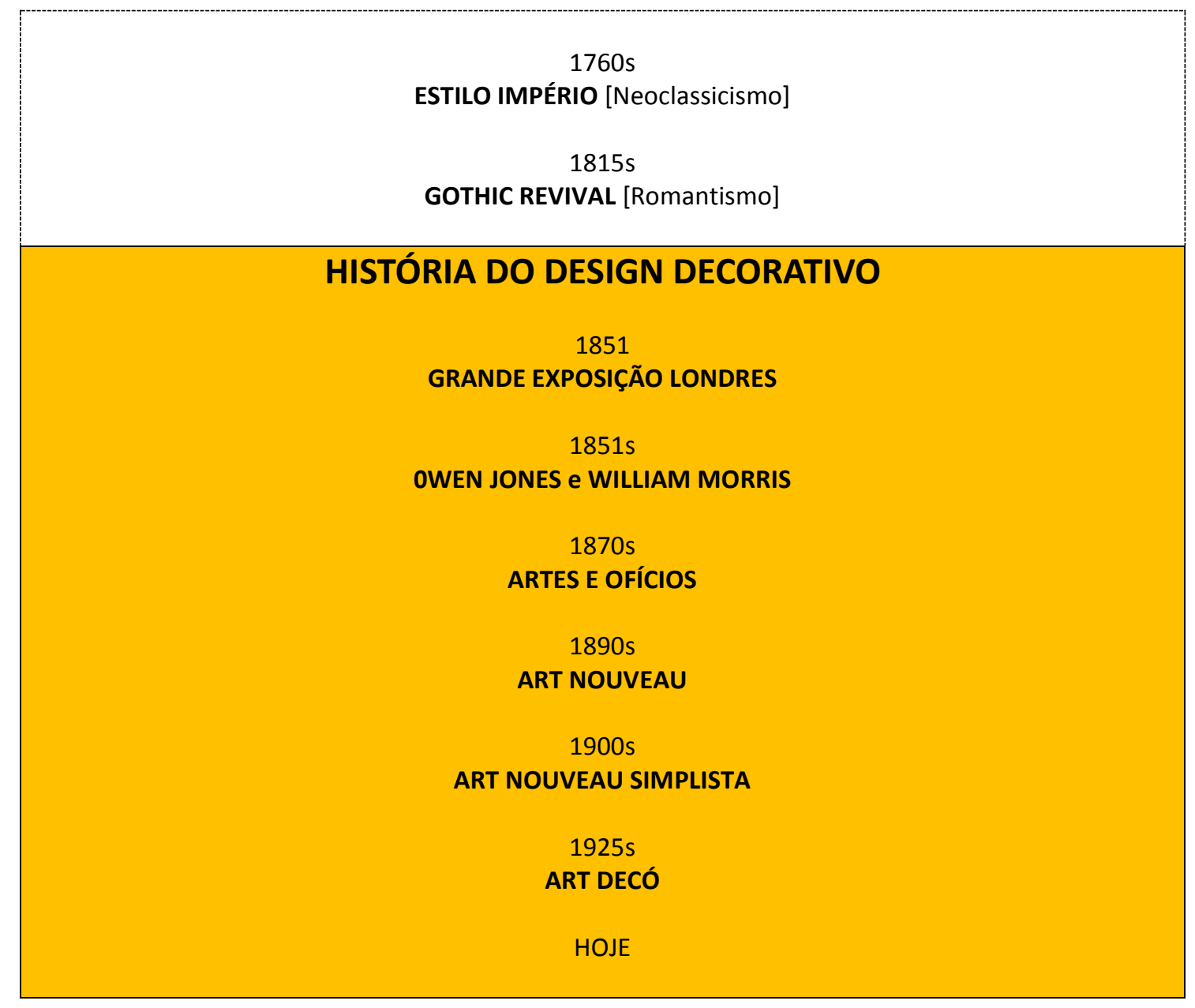

Figura 2 - Linha do Tempo da História do Design Decorativo.

Na história do Design Decorativo, contextualizo esses projetos no âmbito do resgate cultural e da manutenção da qualidade ornamental dos produtos [READ, 1961], e não me furto a considerar aqueles objetos que foram projetados mas não foram produzidos industrialmente, como era característico na época dos movimentos Arts and Crafts [PEVSNER, 1980]. 


\subsection{HISTÓRIA DO DESIGN FUNCIONALISTA}

Para a História do Design Funcionalista adoto como marco temporal inicial tanto o Deutsch Werkbund de Hermann Muthesius e Peter Behrens, na Alemanha, quanto o fordismo, nos Estados Unidos. Mas procuro deixar claro que esta linha evolutiva tem uma pré-história nos produtos Shaker, na cerâmica de Wedgwood e nas cadeiras de Michael Thonet. Daí encaminho o curso para a história da Bauhaus, para a história do Estilo Internacional e para a história da escola de Ulm. Aqui também procuro mostrar que o design funcionalista continua vivo até os dias de hoje e sugiro que ele vem assumindo novas facetas, a exemplo do Design Sustentável ou do Design de Serviços, que são estudados em outra disciplina do curso.

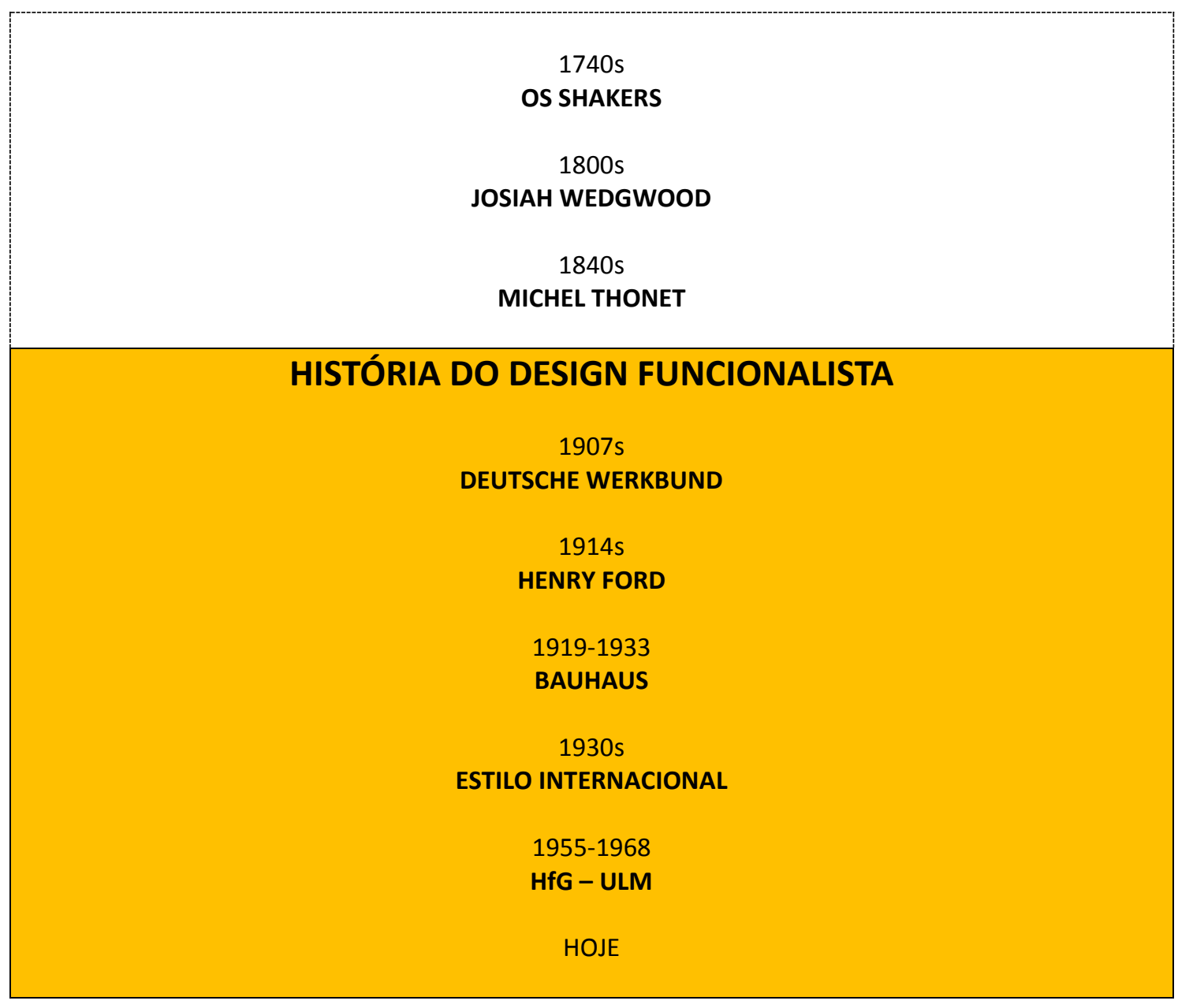

Figura 3 - Linha do Tempo da História do Design Funcionalista.

Na história do Design Funcionalista, caracterizo o design funcionalista como aquela linha evolutiva que "nasce da teoria do funcionalismo, segundo a qual, a forma é determinada pela função e toda decoração é desnecessária - até prejudicial, porque ela atrapalha a produção industrial de massa e aumenta desnecessariamente o custo dos bens manufaturados" [HAUFFE, 1998: 80] e "a crença geral era a de que formas simples e 
geométricas eram mais consistentes com a produção industrial" [Id.: Ibid.]. Contextualizo os produtos funcionalistas nos âmbitos das soluções "técnico-formalistas", "técnicoprodutivista" e "técnico-utilitarista" [MALDONADO, 1993: 59, 69-73].

\subsection{HISTÓRIA DO STYLING}

Para marco temporal do início da História do Styling, não haveria como não adotar o ano do "crack" da bolsa de New York como tal. E como recorte geográfico, o exemplo pioneiro dos designers da américa do norte. Mas aqui também trabalho numa perspectiva préhistórica do Styling, abordando a história de Louis Chevrolet, além de, é óbvio, quase não precisar mostrar que a história do styling continua muito viva.

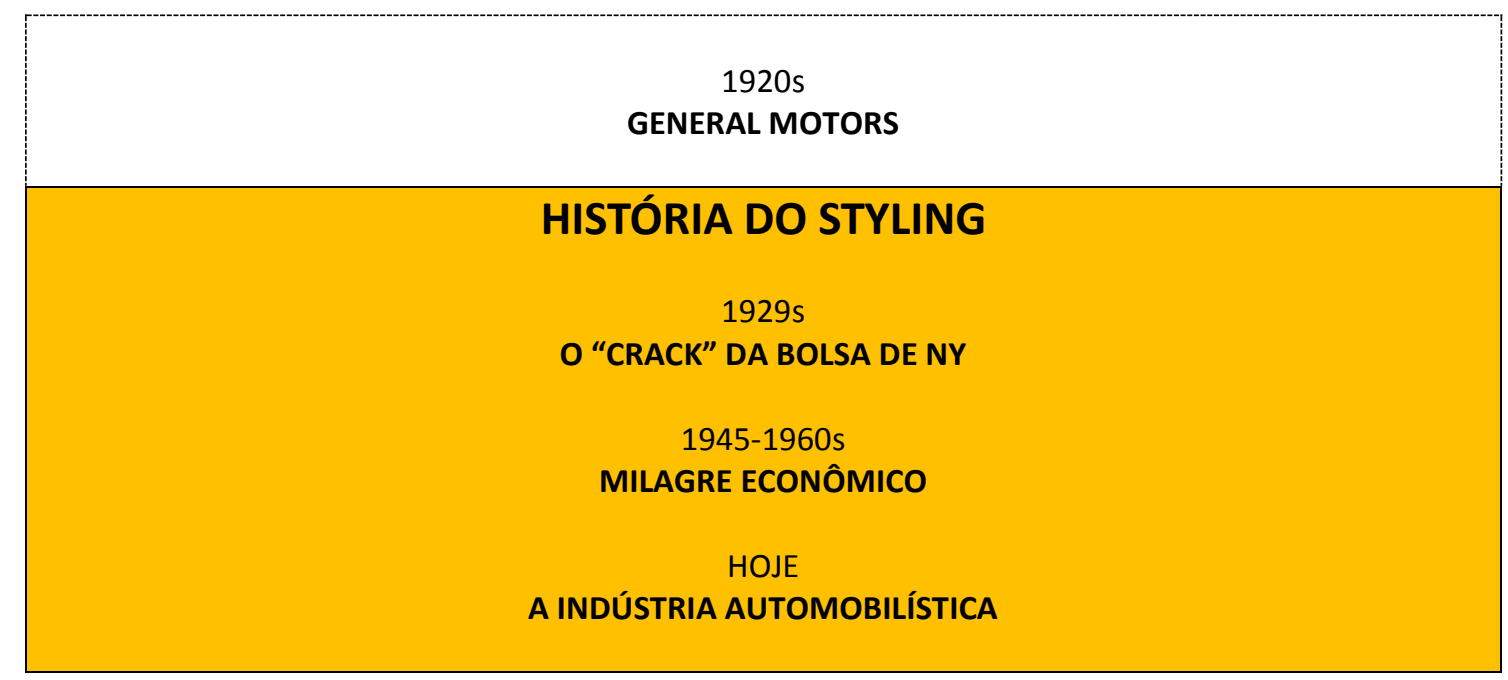

Figura 4 - Linha do Tempo da História do Styling.

A história do Styling é contextualizada no âmbito socioeconômico e considero projetos de styling aqueles produtos que tem sua forma determinada através de uma lógica muito próxima da lógica gratuita da moda [DORFLES, 1978: 59-62]. 


\subsection{HISTÓRIA DO DESIGN PÓS-MODERNISTA}

Por fim, localizo a pré-história do Design Pós-Modernista nos experimentalistas italianos do pós segunda-guerra e marco como seu início as criações dos Designers "Pop", também italianos, dos anos 1960. Atravesso por entre os muitos "studios", "gruppos" e aventuras do Anti-Design-Radical, chego ao Studio Alchimia e ao Gruppo Memphis, ainda na Itália. Daí ao chamado “New Design” [HAUFFE, 1998: 157], na falta de uma denominação melhor, para a internacionalização das estratégias de design características desta linha evolutiva que também é presente.

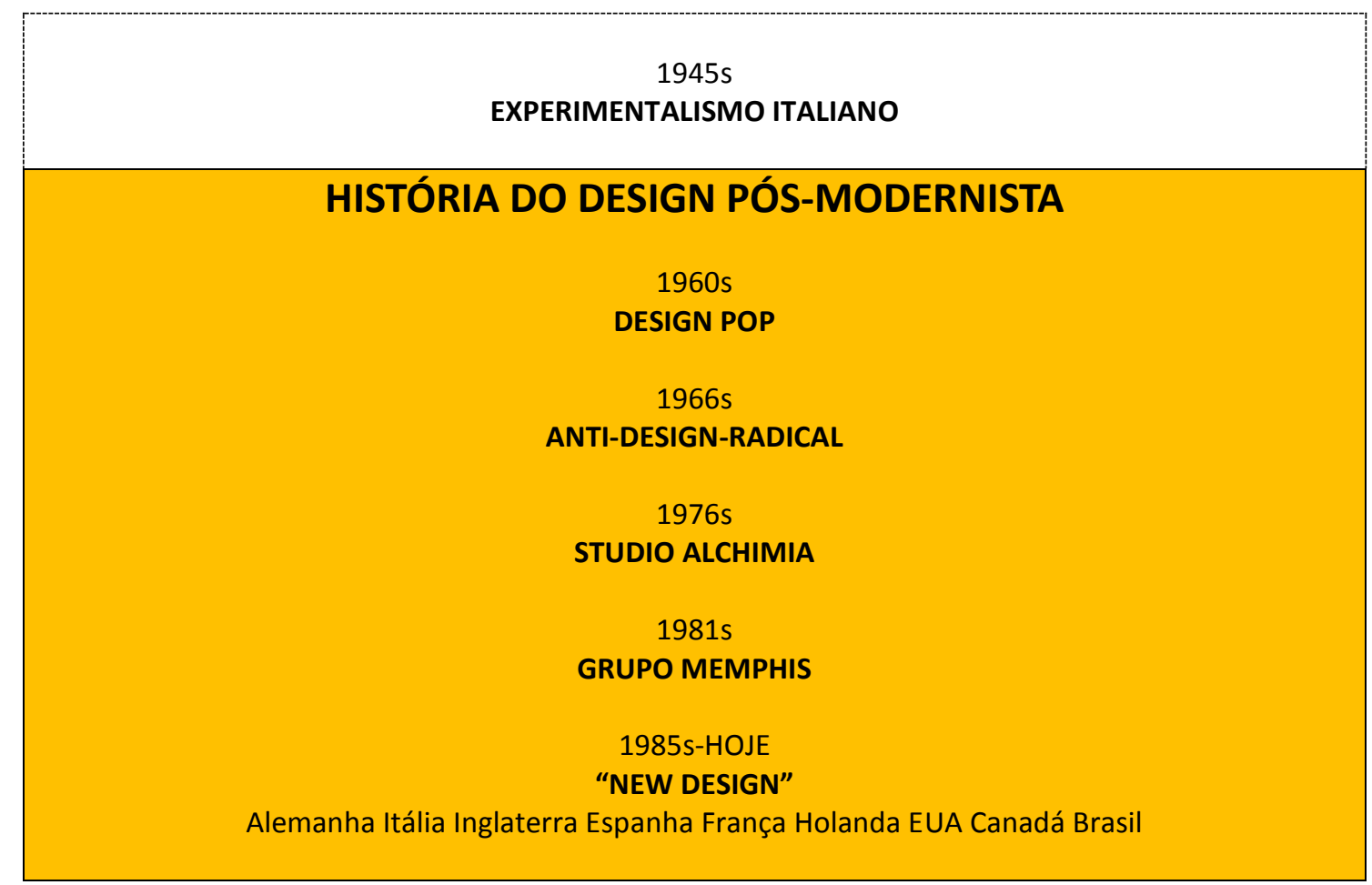

Figura 5 - Linha do Tempo da História do Design Pós-Moderno.

A história do Design Pós-Modernista é contextualizada no âmbito da criação de cultura material e envolve projetos de produtos que, de certo modo, se voltam "contra o funcionalismo bem como contra o domínio da grande indústria e das instituições de design" [HAUFFE, 1998: 141]. 


\section{TIPOS DE AVALIAÇÃO}

Com exceção dos exames finais, desde 2011 todos os trabalhos realizados pelos alunos são do tipo trabalho de pesquisa, que podem ser individuais ou em equipes e que são materializados preferencialmente na forma de vídeos digitais de até 10 minutos.

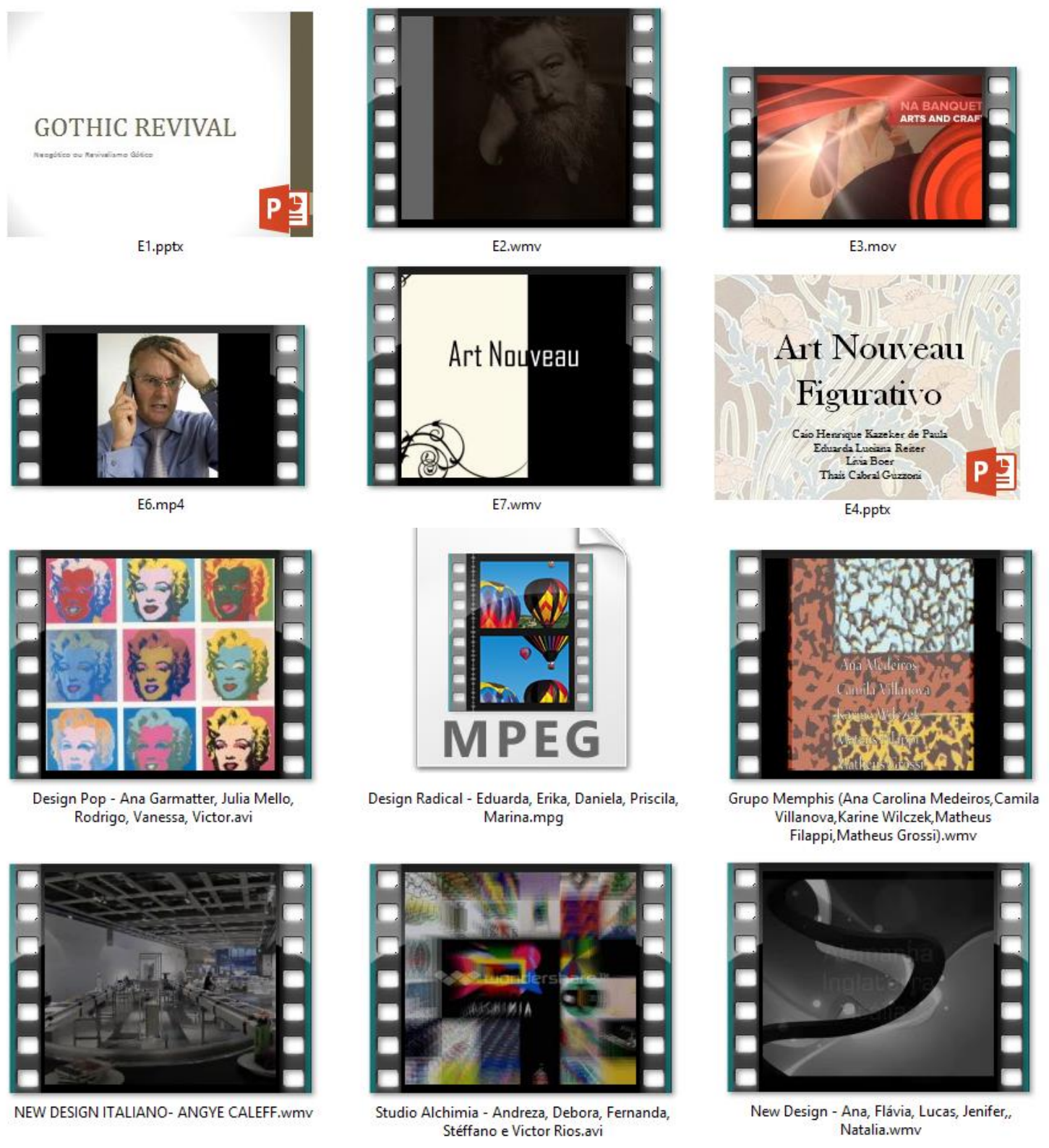

Figura 6 - Ícones de arquivos de filmes escritos, produzidos, dirigidos e montados pelos alunos da disciplina de História do Design de Produto da UFPR.

Escolhi esta estratégia de avaliação porque acabei percebendo que os jovens de 17, 18 anos têm uma facilidade enorme em lidar com a expressão audiovisual. 


\section{REFERÊNCIAS}

DORFLES, Gillo. O Design Industrial e a sua Estética. São Paulo: Martins Fontes, 1978.

HAUFFE, Thomas. Design: a Concise History. London: Laurence King, 1998.

MALDONADO, Tomás. El Diseño Industrial Reconsiderado. $3^{\text {a }}$ ed. Barcelona: Gustavo Gili, 1993.

PEVSNER, Nikolaus. Os Pioneiros do Desenho Moderno: de William Morris a Walter Gropius. São Paulo: Martins Fontes, 1980.

READ, Herbert. Arte e Industria: Principios de Diseño Industrial. Buenos Aires: Infinito, 1961. 